Journal of Mechanical Engineering and Sciences (JMES)

ISSN (Print): 2289-4659; e-ISSN: 2231-8380; Volume 9, pp. 1538-1555, December 2015

(C) Universiti Malaysia Pahang, Malaysia

DOI: http://dx.doi.org/10.15282/jmes.9.2015.2.0150

\title{
Research progresses and future directions on pool boiling heat transfer
}

\author{
M. Kumar, V. Bhutani* and P. Khatak \\ Mechanical Engineering Department, \\ Guru Jambheshwar University of Science \& Technology, \\ Hisar (India)-125001 \\ *Email: vijay.bhutani.24@ gmail.com \\ Phone: +911662263564; Fax: +911662276025
}

\begin{abstract}
This paper reviews the previous work carried on pool boiling heat transfer during heating of various liquids and commodities categorized as refrigerants and dielectric fluids, pure liquids, nanofluids, hydrocarbons and additive mixtures, as well as natural and synthetic colloidal solutions. Nucleate pool boiling is an efficient and effective method of boiling because high heat fluxes are possible with moderate temperature differences. It is characterized by the growth of bubbles on a heated surface. It occurs during boiling of liquids for excess temperature ranging from 5 to $30{ }^{\circ} \mathrm{C}$ in various processes related to high vaporization of liquid for specific purposes like sugarcane juice heating for jaggery making, milk heating for khoa making, steam generation, cooling of electronic equipments, refrigeration and etcetera. In this review paper, pool boiling method during heating of liquids for specific purpose is depicted. It is inferred that enhancement in pool boiling heat transfer is a challenging and complex task. Also, recent research and use of various correlations for natural convection pool boiling is reviewed.
\end{abstract}

Keywords: Pool boiling; nucleate boiling; Rohsenow correlation; heating of liquids; pool boiling correlations.

\section{INTRODUCTION}

Boiling is an effective and efficient mode of heat transfer which is used for the transfer of heat for various heating purposes [1]. Many researches have been done since the 1930's to analyze the boiling process and its characteristics [2, 3]. Rohsenow (1952) proposed correlations for heat flux and heat transfer coefficient for various liquids [4] rosenow. Mostinski, Kutateladze, Labantsov, Kruzhilin, Cooper, Gorenflo, Stephan \& Abdelsalam and many other eminent researchers proposed various pool boiling heat transfer correlations for different liquids [5]. Although a lot of research is being carried out on the mechanism of pool boiling, it is not yet accurately understood. Nonlinear mutual interaction between numbers of sub-processes makes the boiling phenomena more complex to understand [6]. The different boiling regimes based on the excess temperature are nucleate boiling, transition boiling, and film boiling [7, 8].

Nucleate boiling is characterized by the growth of bubbles on a heated surface. The bubbles rise from discrete points on a surface, whose temperature is slightly above the liquid's saturation temperature [9]. Transition boiling (or unstable boiling)s occurs at surface temperature between the maximum attainable temperature in nucleate boiling and the minimum attainable temperature in film boiling. When the heating surface temperature becomes significantly hotter (above $100{ }^{\circ} \mathrm{C}$ ), film boiling takes place, where 
a thin layer of vapor is formed that acts as insulation and results in reduced heat transfer $[10,11]$. Critical heat flux leads to a drastic rise in heater surface temperature $[9,12,13]$. It is used in various heat exchange systems and in cooling of high-energy-density electronic components [14-16]. Rohsenow [4] proposed the following correlation for pool boiling heat transfer.

$$
q^{\prime \prime}=\mu_{l} h_{f g}\left[g\left(\rho_{l}-\rho_{v}\right) / \sigma\right]^{1 / 2}\left[C_{p l} \Delta T /\left(C_{s f} h_{f g} \operatorname{Pr}_{l}^{n}\right)\right]^{3}
$$

In this review paper, the potential of pool boiling method for heating of liquids for specific purposes has been depicted by considering various researches conducted on pool boiling by many eminent researchers worldwide. Also, recent research and use of various correlations for natural convection pool boiling is reviewed. Various applications, advantages, disadvantages, and future research directions of pool boiling are also depicted. Earlier reviews on boiling are summarized in Table 1.

Table 1. Reviews on pool boiling

\begin{tabular}{ccl}
\hline Authors & Year & \multicolumn{1}{c}{ Remarks } \\
\hline$[7]$ & 1998 & Advancement in predicting boiling heat fluxes \\
{$[17]$} & 2004 & Pool boiling heat transfer under reduced gravity. \\
{$[18]$} & 2005 & Influence of lubricants on HT of the refrigerants \\
{$[19]$} & 2008 & Pool boiling heat transfer to HC and $\mathrm{NH}_{4}$ in refrigeration \\
{$[20]$} & 2011 & Boiling HT performance of refrigerants mixtures \\
{$[21]$} & 2011 & Boiling heat transfer enhancement with nanofluids \\
{$[22]$} & 2011 & Statistical analysis of anomalous HT of nanofluids \\
{$[23]$} & 2011 & Progress on nucleate boiling of nanofluids \\
{$[24]$} & 2011 & Critical heat flux enhancement for nanofluids \\
{$[25]$} & 2012 & Pool boiling experiment of multi-component mixtures \\
{$[26]$} & 2012 & Numerical simulation of pool boiling fundamentals \\
{$[27]$} & 2013 & Fundamental issues of critical heat flux \\
\hline
\end{tabular}

\section{RESEARCH CONDUCTED ON POOL BOILING}

Nucleate pool boiling is a significant method of heat transfer at high rate and thus is studied by various researchers. Various liquids and commodities categorized as refrigerants and dielectric fluids, pure liquids, nanofluids, hydrocarbons and additive mixtures, and natural and synthetic colloidal solutions used for carrying out the research on pool boiling for different purposes have been reviewed in the following sections. 


\section{Refrigerants and Dielectric Fluids}

The heat transfer coefficients with the method of regression analysis in natural convection boiling for water, hydrocarbons, cryogenic fluids, and refrigerants were predicted [28, 29]. In addition, the effect of microgravity on pool boiling of Freon 12 and Freon 113 were studied [30]. A correlation was also formulated for the calculation of heat flux density of refrigerants R-113 and R-114 in pool boiling at atmospheric pressure condition [8]. The effects of lubricant mass fraction, viscosity, and miscibility on the pool boiling heat transfer performance of 134a/lubricant mixture with the regression method for 12 different mixtures were reported [31]. A numerical simulation model for heat transfer during boiling of FC-72 based on a numerical macro-layer model was presented [32]. Nucleate pool boiling experiments were performed for pure R-11 with a constant wall temperature condition [33]. Nucleate pool boiling of R-11 on cylindrical copper surfaces at reduced pressure was investigated [34]. The Rohsenow correlation was applied to nucleate boiling of halocarbon refrigerants over cylindrical surfaces and a correlation was developed [35].

The relationship between the flow [29]behavior induced by ultrasonic vibration along with the consequent heat transfer enhancement in natural convection and pool boiling regimes for FC-72 was presented by [17]. The influence of thermo-physical properties on pool boiling heat transfer performance of refrigerants within the evaporator of a refrigeration system was experimentally investigated [36]. The influence of uniform DC electric field on nucleate boiling heat transfer of n-pentane, R-113, and R-123 on a horizontal copper surface was experimentally studied [37]. The pool boiling data for mixtures of R-22/ R-124 on plain tubes at reduced pressures was reported [38]. The pool boiling heat transfer of FC-72 at different pressures on a plain plate heater $\left(15 \times 15 \mathrm{~mm}^{2}\right)$ was studied [39]. The pool boiling heat transfer performance of ammonia within the evaporator of a refrigeration unit with the use of existing correlations was assessed experimentally [40]. A correlation for heat transfer coefficient in the nucleate region based on the Buckingham $\pi$ theorem for Geva-T and low finned tube was estimated for five liquids (R-113, n-pentane, ethanol, water, and R-11) boiling at atmospheric pressure [41].

The effect of surface roughness on nucleate pool boiling of refrigerant R-113 on horizontal circular copper heating surfaces was experimentally investigated [42]. The effects of surface material (copper, brass, and aluminium) on nucleate boiling heat transfer of R-113 were reported [43]. The experimental investigation of nucleate pool boiling of R-134a and R-123 on enhanced smooth tubes of shell type heat exchangers was presented [44]. The boiling of distilled water, ethanol, R-113, and R-123 on heating surfaces covered with copper fibrous capillary porous structures used in heat pipes with porosity $(40 \%, 70 \%$, and $85 \%)$ was investigated experimentally and theoretically [45]. The effect of surface roughness on nucleate boiling heat transfer was studied [46]. Boiling performance of aqueous ammonium chloride as an additive using a nichrome wire heater was experimentally studied [47]. The nucleate boiling heat transfer of gas saturated FC72 on micro pin finned surface under microgravity was investigated [48]. The guidelines for the design of boiling test for FC-72 dielectric fluid on thin horizontal substrates having large number of artificial nucleation sites were presented [49]. The pool boiling curve of R-14 under 0.1 MPa pressure was experimentally studied [50].

Efficient boiling of the refrigerants is very necessary for the effective refrigeration system. Various researches are being carried out worldwide to explore different methods to enhance the boiling performance of refrigerants. Nucleate boiling under reduced gravity, varying pressures, and different boiling surface roughness has been used to 
enhance boiling performance. Modified surfaces and increased nucleation sites on the boiling surface are reported to be effective technique to enhance the boiling characteristics of refrigerants.

\section{Pure Liquids}

Pure Liquids are not contaminated with other substances. Some of the pure liquids are pure water, ethanol, benzene, and etcetera. The boiling heat transfer data employed to water and electric heating methods used by various researchers were compared and discussed [51]. A numerical simulation model for heat transfer during boiling of water based on a numerical macro-layer model was presented [32]. The analysis of a sequence of temperature fields obtained from a nucleate pool boiling experiment was investigated [52]. Nucleate pool boiling of distilled water, benzene, and toluene from a horizontally laid plain stainless steel heating tube at atmospheric and sub-atmospheric pressures was experimentally studied [14]. The lateral merger of bubbles during nucleate pool boiling of water was numerically studied [53]. Saturated pool boiling curve for water on a temperature controlled thin copper strip using Couple Map Lattice method in non-linear spatio-temporal chaos dynamics was reproduced [54]. Experiments were conducted to investigate the efficiency of two distinctly different heat transfer enhancement methods using a thin vessel coating and an enhanced insulation structure for external reactor vessel cooling under severe accidental conditions [55]. Nucleate pool boiling characteristics during pool boiling of sub-cooled water on very small wires were studied [56]. The nucleate boiling of saturated water at high heat fluxes was numerically studied [57]. Nucleate pool boiling heat transfer coefficient for several pure liquids on a horizontal rod heater at atmospheric pressure was experimentally measured [6]. The boiling performance characteristics at atmospheric and sub-atmospheric pressures were experimentally investigated [58]. An experimental estimate of the heat flux for pool boiling of water and methanol at atmospheric pressure in a beaker with varying voltage using Rohsenow correlation with regression analysis was presented [59].

A pool boiling experiment with demineralized water on rough surfaces of the tubes gave almost double heat transfer coefficient [60]. The investigation of nucleate boiling phenomena for distilled water at saturated as well as sub-cooled conditions was presented [61]. The potential of the acoustic emission in detection of bubbles to point out the transition zones during boiling process was examined [62]. Heat transfer characteristics of water through pool boiling over flat stainless steel plate heater using Stephen and Abdelsalam correlation (1980) by optimizing values of power index and coefficient was presented [63]. The effect of design parameters on pool boiling heat transfer for water on sintered tube surfaces was experimentally studied [64]. The pool boiling heat transfer performance of de-ionized water on horizontal plates sintered with copper fiber of various geometries under atmospheric pressure was experimentally investigated [65]. Heat transfer characteristics of water through pool boiling over horizontal stainless steel tube heater upto CHF were studied [66]. The pool boiling heat transfer enhancement by adding environment-friendly surfactants to pure water was experimentally described [67]. A study on heat transfer during pool boiling of water at atmospheric pressure over enhanced cylindrical micro-channel test surfaces was carried out [68]. A 2-D numerical simulation on nucleate boiling with help of VOSET method was presented [69]. Pool boiling experiments with synthetic diamond and silicon carbide heaters using water as the boiling liquid under atmospheric pressure was presented [70]. A model predicting the changes in bubble diameter during pool boiling of distilled water using neural networks in modeling with complicated nonlinear relations was presented 
[71]. Critical heat flux triggering mechanism and dynamic behavior of dry areas in a horizontal pool boiling of saturated water on a transparent indium tin oxide heating surface was observed [72]. The boiling heat transfer behavior of distilled water on horizontal heating surface under atmospheric and sub atmospheric pressure was studied [73].

The effect of microlayer evaporation on heat transfer characteristics for water and ethanol by measuring microlayer thickness formed under a growing bubble was presented [74]. The pool boiling heat transfer characteristics of water on a stainless steel heater was experimentally analyzed [75]. The surface wettability and bubble dynamics during pool boiling of one-component fluids was investigated [76]. A heat transfer enhancement method during cooling of microelectronic elements by the application of ultrasonic fields using wires of different diameters in a pool of subcooled water was presented [77]. A relation for nucleate boiling heat transfer of water through the solid-liquid interface using experimental data was derived and was compared to the existing correlations [78]. A model was proposed to describe the accurate behavior of bubble departure during saturated pool boiling of pure water and ethanol under atmospheric pressure conditions [79]. The pool boiling heat transfer characteristics of water using different treated heating surfaces was studied [80]. Many industrial and commercial processes involve boiling of pure liquids like water, ethanol, Benzene, distilled water, and etcetera. Steam generations, cooling of electronic equipments and others. are the processes where the evaporation of pure liquids is done to absorb high amount of heat generated. Many researchers have discussed various modifications in heating surfaces and use of different pure liquids to enhance pool boiling performance by improving boiling characteristics, i.e. heat flux, critical heat flux, heat transfer coefficient, bubble growth and their departure. Performance of various heaters has been experimentally analyzed to achieve better heat transfer.

\section{Nanofluids}

The nanofluids are engineered colloidal suspension of nanoparticles in a base fluid. The nanoparticles are made of metals, oxides, carbides, and etcetera [81-83]. The boiling heat transfer characteristics of different alumina nano-particle concentrations with water on a horizontal flat smooth surface were studied [84]. Pool boiling heat transfer using nanofluids ( $\gamma$-alumina nanoparticles, $10-50 \mathrm{~nm}$ ) was experimentally investigated [84]. [85]. Pool boiling CHF enhancement in nanofluids by forming a porous layer of nanoparticles on the heater surface was presented [86]. Pool boiling heat transfer of $\mathrm{ZrO}_{2}$ based aqueous nanofluids at low volume fraction of solid dispersion was observed [87]. Decreased heat transfer during pool boiling of diluted suspensions of sphere-shaped titania and alumina particles suspended in ethylene glycol-water mixtures was reported [88]. The mechanism of surface coating during nucleate boiling of nanofluids was experimentally explored [89]. A pool boiling heat transfer model for nanofluids based on fractal distribution of nanoparticles and nucleation sites on boiling surfaces was presented [90]. The heat transfer characteristics of $\mathrm{CuO}$ nanofluids for low concentrations and at/above atmospheric pressures were experimentally studied and enhanced critical heat flux was observed [91-94]. The pool boiling heat transfer under heating surface with various interlaced wettability using nano-silica particles as the coating element was investigated [95]. A theoretical correlation for pool boiling of $\mathrm{TiO}_{2}$-water nanofluid solution on a stainless steel flat heating surface was developed [96-99]. A correlation for predicting heat transfer coefficient for nucleate pool boiling of $\mathrm{TiO}_{2}$-water nanofluids at 
several low concentrations using two horizontal circular plate heaters having different surface roughness was presented [100].

The pool boiling heat transfer for saturated water over nanoparticle modified aluminium surfaces having different surface wettability were investigated [101]. During pool boiling experiments on $\mathrm{ZnO}$ nanoparticles concentrations with water at atmospheric pressure on an electrically heated $\mathrm{Ni}-\mathrm{Cr}$ wire, 70 to $80 \%$ enhancement in critical heat flux for pure water was reported [102]. Enhancement in pool boiling heat transfer was observed by creating one-dimensionally grown alumina nano porous surface [103]. An empirical correlation was developed to predict the heat flux for nucleate pool boiling of nanofluids [104]. The effect of nanorod length on pool boiling heat transfer for water was experimentally studied [105]. The influence of nanoparticles on the pool boiling heat transfer in open-celled foams at atmospheric pressure was investigated [106]. Heat transfer characteristics during pool boiling of nanofluids on cylindrical surface were investigated and it was observed that the heat transfer coefficient depends upon nanoparticle concentration and boiling pressure [107]. Various nanofluids are being used as additives in pure liquids or as surface coating on the heating surfaces to enhance the heat transfer characteristics. From the literature, it has been observed that low concentrations of nanoparticles in pure liquids cause enhancement in boiling performance, whereas reduction in heat transfer is observed at high concentrations of nanoparticles. Thus, determining the optimal concentration of nanoparticles becomes a challenging task, which significantly affects the pool boiling heat transfer.

\section{Hydrocarbons and Additive Mixtures}

Hydrocarbon, an organic compound consisting of hydrogen and carbon, is the primary energy source for current civilization and is mainly classified into saturated hydrocarbons (Alkanes) and unsaturated hydrocarbons (Alkenes and alkynes). Additive mixtures of two or more liquids are being used in various heat transfer applications to obtain desired properties. An estimation method to predict the heat transfer of nucleate pool boiling in binary mixtures using Colburn analogy was described [108]. An experimental study to determine the effects of binary diffusion and surface tension on the pool boiling heat transfer of dilute aqueous solution of ethylene glycol was presented [109]. The boiling curves obtained for various concentrations of water with cationic surfactant were compared [110]. The heat transfer coefficients of different mixtures were reported lower than those obtained for pure components constituting the mixture for a given heat flux [111]. The influence of thermo-physical properties on pool boiling heat transfer of hydrocarbons (propane and i-butane) within the evaporator of a refrigeration system (Figure 1) was experimentally investigated and compared to data available in the literature [36]. The heat transfer and boiling temperature of different concentration levels of sugar-water solution was studied [112]. Nucleate boiling heat transfer coefficients of mixtures of water-monoethanolamine and water-diethanolamine on a horizontal heating rod at atmospheric pressure were experimentally measured [113]. . Schematic diagram of Gorenflo pool boiling apparatus is shown in Figure 2. Heat transfer coefficient for the nucleate pool boiling of methanol, distilled water, and their mixtures on a plain as well as copper-coated stainless steel tubes at atmospheric and sub-atmospheric pressures were measured [114].

Experiments were conducted to enhance pool boiling heat transfer by adding ammonium chloride as a surfactant in pure water [115]. The heat transfer in saturated nucleate pool boiling of the water/lithium bromide mixture on a uniformly heated vertical cylinder at a pressure of 2 bar was reported [116]. Nucleate pool boiling heat transfer 
coefficient of ternary mixtures of ethanol, monoethylene glycol, and diethyleneglycol as a new coolant with higher heat transfer coefficient was investigated [117]. An experimental study on n-pentane nucleate boiling at atmospheric pressure and saturation temperature for different gap sizes (Figure 3 ) in a confined space was conducted [118].

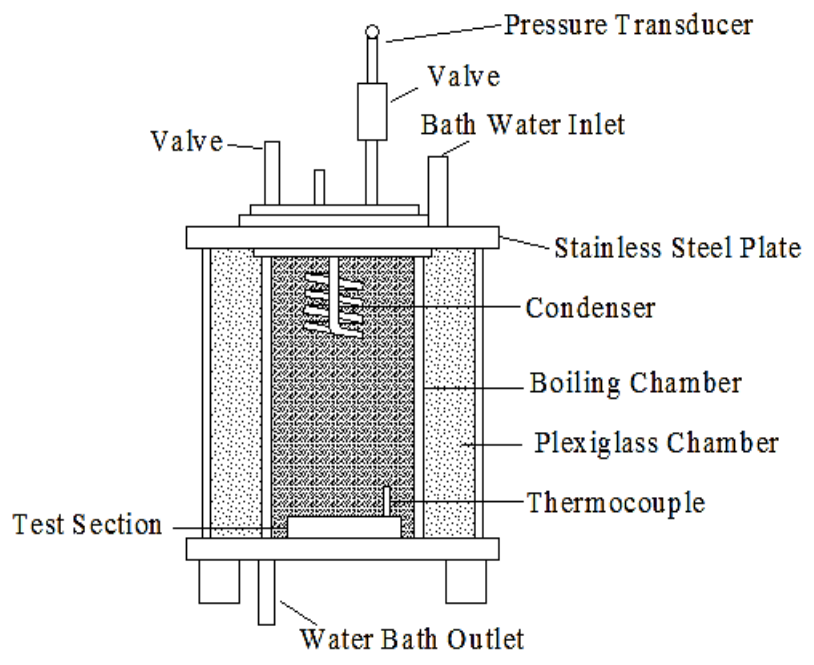

Figure 1. Pool boiling setup [98].

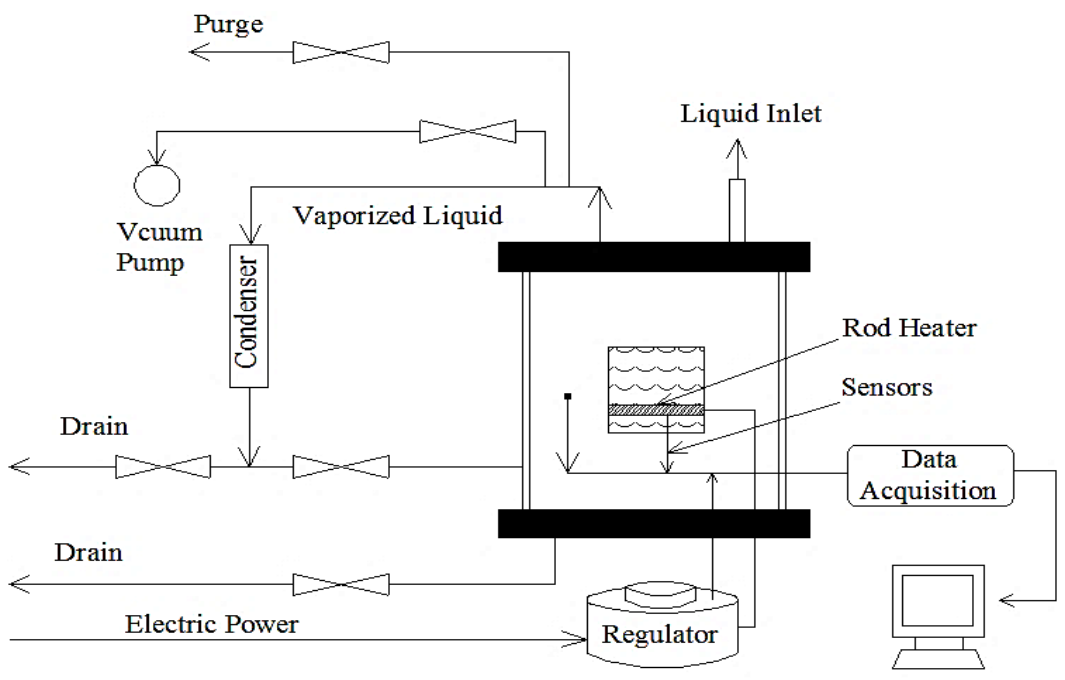

Figure 2. Schematic diagram of Gorenflo pool boiling apparatus [113].

Pool boiling heat transfer in water/glycerol binary solution on a horizontal rod heater for various concentrations at atmospheric pressure was studied [119]. Various correlations for predicting the pool boiling heat transfer coefficient of FK-649 at various saturation conditions were compared to replace engineered fluids [120]. Pool boiling investigation of PF-5060 under reduced gravity and a pressure of 600 mbar was presented [121]. The bubble departure diameters during saturated pool boiling of various binary mixtures under atmospheric pressure conditions were reported [79]. The boiling heat transfer coefficient for nicrome wire immersed in saturated water with and without various concentrations of 2-Ethyl 1-Hexanol as an additive was evaluated [122]. The prediction of pool boiling heat transfer coefficient for multi-component system using 
artificial neural network method was reported [123]. From the literature, it has been concluded that various binary and ternary mixtures are used to enhance the heat transfer performance. Higher heat transfer coefficients are obtained with the suitable mixtures of hydrocarbons and other commercial liquids as compared to pure liquids.

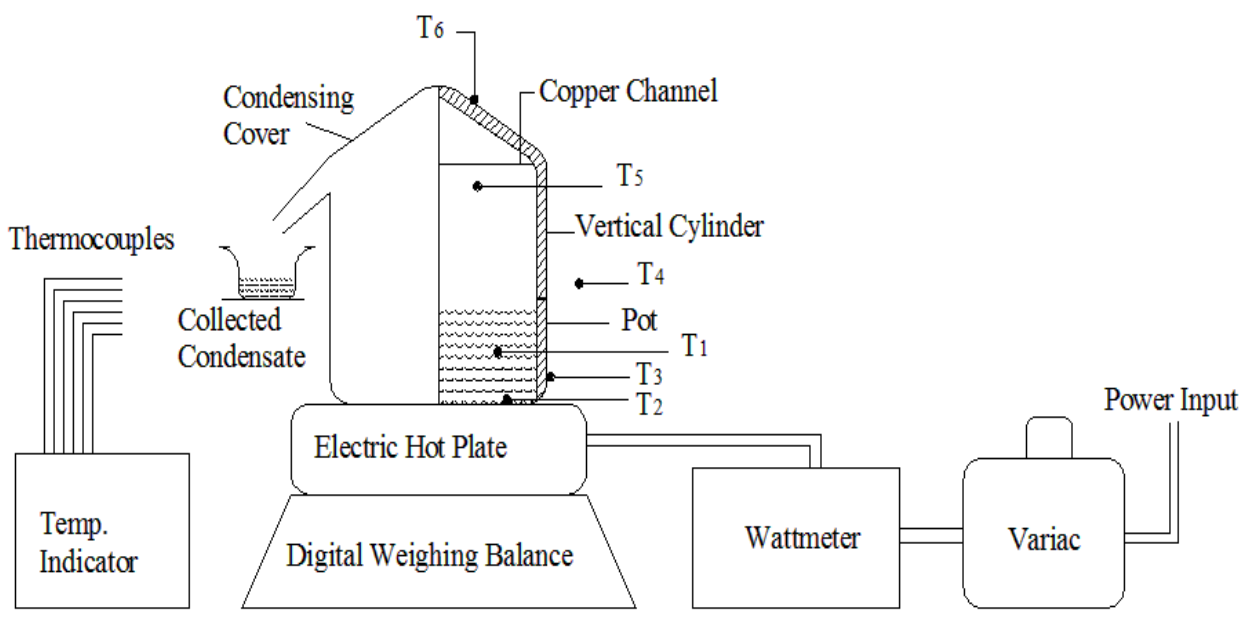

Figure 3. Pool boiling under closed conditions [105, 106].

\section{Natural and Synthetic Colloidal Solutions}

A colloidal solution is a mixture of a colloid microscopically dispersed throughout another substance. Particles in colloidal solution are smaller and do not settle, distinguishing it from suspension. The major natural colloidal solutions widely used in food processing are milk and sugar cane juice. Milk is an emulsified colloid of liquid butterfat globules dispersed with a water-based solution. Sugar cane juice is an extremely complex liquid medium containing many organic and inorganic constituents in soluble and colloidal form. The pool boiling of sugar cane juice in an aluminium pot heated by an electric hot plate using regression analysis by applying Rohsenow correlation was studied [124]. Pool boiling of milk under open and closed conditions (Figure 4) in aluminum and stainless steel pots has been studied using Rohsenow correlation with the help of linear regression analysis for different heat inputs [125-128]. The convective heat transfer coefficient and heat flux were reported to increase with the increased heat input. The average values of fluid-surface constant $C_{s f}$ for Rohsenow pool boiling correlation during khoa making in an aluminum and stainless steel pot were evaluated as $7.8815 \times 10^{-3}$ and $9.4772 \times 10^{-3}$ respectively [129]. From the above literature, it has been observed that pool boiling behavior of natural colloidal solutions, namely milk and sugarcane juice, was studied by applying Rohsenow correlation. Heat transfer coefficient during pool boiling was reported to increase with increased heat inputs. Heat transfer performance was observed to be dependent on proper selection of pot material and heating conditions. In synthetic colloidal solutions, the heat transfer and CHF were found to be dependent on the solution's concentration.

\section{POOL BOILING APPLICATIONS AND ITS CORRELATIONS}

Pool boiling is an adequate technique for many heat transfer applications because of high heat transfer and high heat flux at moderate temperatures. Some of the applications of 
pool boiling are: purification of water by boiling, steam generation by rapid evaporation for various industrial purposes [130], refrigeration system and evaporation of various liquids like refrigerants for industrial purposes, petroleum oil refineries, cooling of electronic equipments [131, 132], processing of milk for khoa making [125-129], processing of sugarcane juice for jaggery making [124], fluid handling and control system, cooling of nuclear reactor system [133], heat transfer and optimal system design [134], as well as impulse drying of paper web in paper industry [135], and others. Major existing correlations for prediction of pool boiling heat transfer coefficient are listed in Table 2.

Table 2. Pool boiling correlations.

\begin{tabular}{|c|c|c|}
\hline Researchers & Correlations & Applications \\
\hline$[4]$ & $q^{\prime \prime}=\mu_{l} h_{f g}\left[g\left(\rho_{l}-\rho_{v}\right) / \sigma\right]^{1 / 2}\left[C_{p l} \Delta T /\left(C_{s f} h_{f g} \operatorname{Pr}_{l}{ }^{n}\right]^{3}\right.$ & $\mathrm{PL}, \mathrm{R}, \mathrm{HC}, \& \mathrm{CS}$ \\
\hline [28] & $h=0.23\left(k_{l} / d_{b}\right) A^{0.674} B^{0.297} C^{0.371} D^{0.35} E^{-1.73}$ & $\mathrm{~W}, \mathrm{O}, \mathrm{R}, \& \mathrm{C}$ \\
\hline$[136]$ & $h=0.00417\left(q^{" 1}\right)^{0.7} p_{c}^{0.69} F_{p}$ & $\mathrm{PL}, \mathrm{R}, \& \mathrm{HC}$ \\
\hline [137] & $h=0.075\left[1+10\left(\frac{\rho_{v}}{\rho_{l}-\rho_{v}}\right)^{0.67}\right]\left[\frac{k_{l}^{2}}{v \sigma T_{s}}\right]^{0.33}\left(q^{\prime \prime}\right)^{0.67}$ & $\mathrm{PL}, \mathrm{R}, \& \mathrm{HC}$ \\
\hline$[138]$ & $h=\left[3.37 E-9\left(k_{l} / l\right)\left\{h_{f g} /\left(C_{p l} q^{\prime \prime}\right)\right\}^{-2} M^{-4}\right]^{1 / 3}$ & $\mathrm{NF}, \mathrm{W}, \& \mathrm{HC}$ \\
\hline [139] & $h=0.082 \frac{k_{l}}{l}\left[\frac{h_{f g} q^{\prime \prime}}{g T_{s} k_{l}}\left(\frac{\rho_{v}}{\rho_{l}-\rho_{v}}\right)\right]^{0.7}\left[\frac{T_{s} C_{p l} \sigma P}{h_{f g} \rho_{v} l}\right]$ & $\mathrm{HC}, \mathrm{W}, \& \mathrm{BM}$ \\
\hline [140] & $h=55 \operatorname{Pr}^{0.12-0.4343 \ln R_{p}}(-0.4343 \ln \operatorname{Pr})^{-0.55} M^{-0.5}\left(q^{\prime \prime}\right)^{0.67}$ & $\mathrm{R}, \mathrm{PL}, \& \mathrm{LM}$ \\
\hline [141] & $h=h_{o} F_{p}\left(q^{\prime \prime} / q_{o}\right)^{f}\left(R_{p} / R_{p o}\right)^{0.133}$ & $\mathrm{R} \& \mathrm{HC}$ \\
\hline [142] & $N u=9.7 p_{c}{ }^{0.5} F_{p} \operatorname{Re}^{0.67} \operatorname{Pr}^{0.4}$ & NF, PL, \& R \\
\hline [143] & $q^{\prime \prime}=(\pi / 24) h_{f g}\left[\sigma g\left(\rho_{l}-\rho_{v}\right) / \rho_{v}{ }^{2}\right]^{0.25}\left[1+\left(\rho_{v} / \rho_{l}\right)\right]^{0.5}$ & $\mathrm{~W} \& \mathrm{NF}$ \\
\hline \multicolumn{3}{|c|}{$\begin{array}{l}\mathrm{PL}=\text { Pure liquids, } \mathrm{R}=\text { Refrigerants, } \mathrm{HC}=\text { Hydrocarbon, } \mathrm{CS}=\text { Colloidal Solutions, } \mathrm{W}= \\
\text { Water, } \mathrm{O}=\text { Organic fluids, } \mathrm{C}=\text { Cryogenic fluids, } \mathrm{NF}=\text { Nanofluids, } \mathrm{BM}=\text { Binary } \\
\text { mixtures, } \mathrm{LM}=\text { Liquid mixture }\end{array}$} \\
\hline
\end{tabular}

\section{CONCLUSIONS}

Pool boiling is an effective and efficient method of heat transfer to liquids. Efficient boiling of the refrigerants is very necessary for an effective refrigeration system. Nucleate boiling under reduced gravity, varying pressures and different boiling surface roughness have been used to enhance boiling performance. Modified surfaces and increased nucleation sites on the boiling surface are found to be effective techniques to enhance the 
boiling characteristics of refrigerants. Various modifications in heating surfaces and use of pure liquids are found to enhance pool boiling performance by improving boiling characteristics, i.e. heat flux, critical heat flux, heat transfer coefficient, bubble growth and departure, and etcetera. Nanofluids are being used as additives in pure liquids or as surface coating on the heating surfaces to enhance the heat transfer characteristics. Boiling performance enhancement in pure liquids has been observed at low concentrations of nanoparticles. Various binary and ternary mixtures are also used to enhance the heat transfer performance. Higher heat transfer coefficients are obtained with the suitable mixtures of hydrocarbons and other commercial liquids. A correct and significant correlation for heat flux and heat transfer coefficient calculation is still a challenge to be explored. A concerted effort is required to search the optimum mathematical modeling and numerical analysis techniques to predict the inter-relative behavior of the sub-processes involved in boiling. Nanoparticles coatings of different layer thickness applied to the heater surface can be analyzed optimally to enhance the pool boiling heat transfer. Use of acoustic fields, electromagnetic fields, and ultrasonic vibrations can be optimized for the heat transfer enhancement for various liquids. Analysis and design of irregular geometrical corrugation on the heating surfaces can be performed to achieve heat transfer enhancement.

\section{ACKNOWLEDGEMENTS}

The authors would like to thanks to Guru Jambheshwar University of Science \& Technology, India for assistance and support.

\section{REFERENCES}

[1] Kumar M, Prakash O, Samsher. Review paper on methods of enhancement of pool boiling heat transfer. 14th ISME International Conference on Mechanical Engineering in Knowledge Age. Delhi. 2005; p. 905-8.

[2] Westwater J. Boiling heat transfer. American Scientist. 1959;47:427-46.

[3] Han CY, Griffith P. The mechanism of heat transfer in nucleate pool boiling. Cambridge, Mass.: MIT Division of Sponsored Research,[1962]; 1962.

[4] Rohsenow W. A method of correlating heat-transfer data for surface boiling of liquids. Technical report (Massachusetts Institute of Technology),. 1952;74:96976.

[5] Bejan A, Kraus AD. Heat transfer handbook: John Wiley \& Sons; 2003.

[6] Fazel SA, Roumana S. Pool boiling heat transfer to pure liquids. WSEAS Conference, USA2010.

[7] Dhir V. Boiling heat transfer. Annual Review of Fluid Mechanics. 1998;30:365401.

[8] Gu J, Lu M. The new assumption for calculating heat transfer in pool boiling. Heat and mass transfer. 1999;35:295-7.

[9] Boiling heat transfer on external surfaces: Wolverine Tube Inc. Engineering thermal Innovation; 2006.

[10] PK N. Heat and mass transfer: Tata Mcgraw Hill Education Private Limited,; 2011.

[11] Brumfield LA. Pool boiling enhancement via micro ratchets [MS thesis]: Louisiana State University; 2011. 
[12] Kandlikar SG. Critical heat flux in subcooled flow boiling-an assessment of current understanding and future directions for research. Multiphase Science and Technology. 2001;13:207-32.

[13] Katto Y. Critical heat flux. International Journal of Multiphase Flow. 1994;20:5390.

[14] Bhaumik S, Agarwal V, Gupta S. A generalized correlation of nucleate pool boiling of liquids. Indian Journal of Chemical Technology. 2004;11:719-25.

[15] Sriraman SR. Pool boiling on nano-finned surfaces [Thesis Report ]: Texas A\&M University; 2007.

[16] Nawi MRM, Mamat AMI, Ismail H. Numerical heat transfer analysis of waste heat exchanger for exhaust gas energy recovery. Journal of Mechanical Engineering and Sciences. 2015;8:1498-506.

[17] Jungho K. Review of reduced gravity boiling heat transfer: US research. Japan Society of Microgravity Application,. 2003;20:264-71.

[18] Eckhard B, Groll A. A critical review of the influence of lubricants on the heat transfer and pressure drop of refrigerants-Part II: Lubricant influence on condensation and pressure drop. HVAC\&R Research. 2005;11:511-26.

[19] Kotthoff S, Gorenflo D. Pool boiling heat transfer to hydrocarbons and ammonia: A state-of-the-art review. International Journal of Refrigeration. 2008;31:573602.

[20] Saidur R, Kazi S, Hossain M, Rahman M, Mohammed H. A review on the performance of nanoparticles suspended with refrigerants and lubricating oils in refrigeration systems. Renewable and Sustainable Energy Reviews. 2011;15:31023.

[21] Barber J, Brutin D, Tadrist L. A review on boiling heat transfer enhancement with nanofluids. Nanoscale Research Letters. 2011;6:280.

[22] Sergis A, Hardalupas Y. Anomalous heat transfer modes of nanofluids: a review based on statistical analysis. Nanoscale Research Letters. 2011;6:1-37.

[23] Chung J, Chen T, Maroo S. A review of recent progress on nano/micro scale nucleate boiling fundamentals. Frontiers in Heat and Mass Transfer. 2011;2:1-19.

[24] Ahn HS, Kim MH. A review on critical heat flux enhancement with nanofluids and surface modification. Journal of Heat transfer. 2012;134:1-13.

[25] Das S, Bhaumik S. Nucleate pool boiling heat transfer in multicomponent mixtures on surfaces: an review. International Journal of Mechanical and Industrial Engineering. 2012;2:98-106.

[26] Kunugi T. Brief review of latest direct numerical simulation on pool and film boiling. Nuclear Engineering and Technology. 2012;44:847-54.

[27] Cheng L. Fundamental issues of critical heat flux phenomena during flow boiling in microscale-channels and nucleate pool boiling in confined spaces. Heat Transfer Engineering. 2013;34:1016-43.

[28] Stephan K, Abdelsalam M. Heat-transfer correlations for natural convection boiling. International Journal of Heat and Mass Transfer. 1980;23:73-87.

[29] Yusof TM, Arshad AM, Suziyana MD, Chui LG, Basrawi MF. Experimental study of a domestic refrigerator with $\mathrm{POE}-\mathrm{Al}_{2} \mathrm{O}_{3}$ nanolubricant. International Journal of Automotive and Mechanical Engineering. 2015;11:2243-52.

[30] Zell M, Straub J, Vogel B. Pool boiling under microgravity. Physico Chemical Hydrodynamics. 1989;11:812-23.

[31] Kedzierski M. Refrigerant/lubricant mixture boiling heat transfer research at NIST. Sixteenth National Convention of Mechanical Engineers and All India 
Seminar on Future Trends in Mechanical Engineering, Research and Development, Dept of Mech \& Ind Eng, UOR, Roorkee2000.

[32] He Y, Shoji M, Maruyama S. Numerical study of high heat flux pool boiling heat transfer. International Journal of Heat and Mass Transfer. 2001;44:2357-73.

[33] Lee HC, Oh BD, Bae SW, Kim MH, Lee JY, Song IS. Partial nucleate boiling on the microscale heater maintaining constant wall temperature. Journal of Nuclear Science and Technology. 2003;40:768-74.

[34] Silva EF, Stelute EB, Jabardo JMS. The effect of the surface condition on nucleate pool boiling of refrigerant R-11 on cylindrical copper surfaces. Silva. 2002;77:0224.0.

[35] Jabardo J, Silva E, Ribatski G, de Barros SF. Evaluation of the Rohsenow correlation through experimental pool boiling of halocarbon refrigerants on cylindrical surfaces. Journal of the Brazilian Society of Mechanical Sciences and Engineering. 2004;26:218-30.

[36] Gorenflo D, Chandra U, Kotthoff S, Luke A. Influence of thermophysical properties on pool boiling heat transfer of refrigerants. International Journal of Refrigeration. 2004;27:492-502.

[37] Zaghdoudi M, Lallemand M. Pool boiling heat transfer enhancement by means of high DC electric field. Arabian Journal for Science and Engineering. 2005;30:189-212.

[38] Chiou CB, Lu DC, Wang CC. Investigations of pool boiling heat transfer of binary refrigerant mixtures. Heat Transfer Engineering. 2007;18:61-72.

[39] Zhao JF, Yan N, Li J, Li ZD, Hu WR, H O. Pool boiling heat transfer in microgravity. Journal of the Japan Society of Microgravity Application. 2008;25:257-60.

[40] Sathyabhama A, Hegde RN. Prediction of nucleate pool boiling heat transfer coefficient. Thermal Science. 2010;14:353-64.

[41] Tarrad AH. A correlation for the prediction of nucleate pool boiling performance of pure liquids from enhanced tubes. Jordan Journal of Mechanical and Industrial Engineering. 2011;5:139-44.

[42] Hosseini R, Gholaminejad A, Jahandar H. Roughness effects on nucleate pool boiling of R-113 on horizontal circular copper surfaces. World Academy of Science, Engineering and Technology. 2011;55:580-5.

[43] Hosseini R, Gholaminejad A, Nabil M, Samadinia MH. Concerning the effect of surface material on nucleate boiling heat transfer of R-113. Journal of Electronics Cooling and Thermal Control. 2011;1:22-7.

[44] Gorgy E, Eckels S. Local heat transfer coefficient for pool boiling of R-134a and R-123 on smooth and enhanced tubes. International Journal of Heat and Mass Transfer. 2012;55:3021-8.

[45] Wojcik T, Poniewski M. Heating surface thermal stabilization for pool boiling on porous coverings. Journal of Physics: Conference Series: IOP Publishing; 2012. p. 012138.

[46] McHale JP, Garimella SV. Nucleate boiling from smooth and rough surfaces-Part 2: analysis of surface roughness effects on nucleate boiling. Experimental Thermal and Fluid Science. 2013;44:439-55.

[47] Gajghate SS, Aacharya AR, Pise AT, Jadhav GS. Experimental study of heat transfer enhancement in pool boiling by using 2-Ethyl 1-Hexanol an additive. Applied Mechanics and Materials: Trans Tech Publ; 2014. p. 1601-6. 
[48] Zhang Y, Wei J, Xue Y, Kong X, Zhao J. Bubble dynamics in nucleate pool boiling on micro-pin-finned surfaces in microgravity. Applied Thermal Engineering. 2014;70:172-82.

[49] Nayak SK, Pattanaik BP. Experimental Investigation on Performance and Emission Characteristics of a Diesel Engine Fuelled with Mahua Biodiesel Using Additive. Energy Procedia. 2014;54:569-79.

[50] Zhao C, Gong M, Ding L, Zou X, Chen G, Wu J. An experimental investigation on the entire pool boiling curve of R14 under $0.1 \mathrm{MPa}$ pressure. International Journal of Refrigeration. 2014;41:164-70.

[51] Darabi J, Ohadi M, Fanni M, Dessiatoun S, Kedzierski M. Effect of heating boundary conditions on pool boiling experiments. HVAC\&R Research. 1999;5:283-96.

[52] McSharry PE, Ellepola JH, von Hardenberg J, Smith LA, Kenning DB, Judd K. Spatio-temporal analysis of nucleate pool boiling: identification of nucleation sites using non-orthogonal empirical functions. International Journal of Heat and Mass Transfer. 2002;45:237-53.

[53] Mukherjee A, Dhir V. Study of lateral merger of vapor bubbles during nucleate pool boiling. Journal of Heat Transfer, ASME. 2004;126:1023-39.

[54] Ghoshdastidar P, Kabelac S, Mohanty A. Numerical modelling of atmospheric pool boiling by the coupled map lattice method. Proceedings of the Institution of Mechanical Engineers, Part C: Journal of Mechanical Engineering Science. 2004;218:195-205.

[55] Yang J, Cheung F, Rempe J, Suh K, Kim S. Correlations of nucleate boiling heat transfer and critical heat flux for external reactor vessel cooling. ASME 2005 Summer Heat Transfer Conference collocated with the ASME 2005 Pacific Rim Technical Conference and Exhibition on Integration and Packaging of MEMS, NEMS, and Electronic Systems: American Society of Mechanical Engineers; 2005. p. 99-108.

[56] Lu F, Peng X, Bourouga B. Nucleate boiling modes of subcooled water on fine wires submerged in a pool. Experimental Heat Transfer. 2006;19:95-111.

[57] Son G, Dhir VK. Numerical simulation of nucleate boiling on a horizontal surface at high heat fluxes. International Journal of Heat and Mass transfer. 2008;51:256682.

[58] Sloan A, Penley S, Wirtz R. Sub-atmospheric pressure pool boiling of water on a screen-laminate enhanced surface. IEEE Semiconductor Thermal Measurement and Management Symposium, 2009; p. 246-53.

[59] Islam MS, Haque KT, Saha SC. An experimental investigation of pool boiling at atmospheric pressure. Daffodil International University Journal of Science and Technology. 2011;6:80-6.

[60] Sarbu I, Valea ES. Correlations for enhanced boiling heat transfer on modified surfaces tubes. International Journal of Energy and Environment. 2011;5:444-51.

[61] Duan X, Buongiorno J, McKrell T. Integrated particle imaging velocimetry and infrared thermometry for high resolution measurement of sub-cooled nucleate pool boiling. The 14th International Topical Meeting on Nuclear Reactor Thermal hydraulics NURETH-14 Toronto Ontario Canada2011.

[62] Carmi R, Bussiba A, Widenfeld G, Aharon Y, Alon I, Hochbaum I. Detection of transient zones during water boiling by acoustic emission. Acoustic Emission. 2011;29:89-97. 
[63] Manikandaprabu B, Mohankumar S, Kathiravan R. Pool boiling of water over a stainless steel flat plate heater. International Journal of Instrumentation, Control and Automation,. 1:2231-1890.

[64] Wen M-Y, Ho C-Y, Jang K-J. An optimal parametric design to improve pool boiling heat transfer of sintered surfaces. Journal of Engineering and Technology Research. 2012;4:49-56.

[65] Qu Z, Li D, Huang J, Xu Z, Liu X, Tao W. Experimental investigations of pool boiling heat transfer on horizontal plate sintered with metallic fiber felt. International Journal of Green Energy. 2012;9:22-38.

[66] Muruganantham R, Vignesh G, Vignesh R, Madhan P, Kathiravan R. Pool boiling characteristics of water over a horizontal stainless steel tube heater. International Journal of Mechanical and Production Engineering. 2013;1:23-9.

[67] Dikici B, Eno E. Environmentally friendly surfactant additives for nucleate pool boiling enhancement. 41st Annual NATAS Conference: Bowling Green, KY 2014.

[68] Mehta JS, Kandlikar SG. Pool boiling heat transfer enhancement over cylindrical tubes with water at atmospheric pressure, Part I: Experimental results for circumferential rectangular open microchannels. International Journal of Heat and Mass Transfer. 2013;64:1205-15.

[69] Ling K, Li Z-Y, Tao W-Q. A direct numerical simulation for nucleate boiling by the VOSET method. Numerical Heat Transfer, Part A: Applications: An International Journal of Computation and Methodolog. 2014;65:949-71.

[70] Kapitz M, Becker A, Wiesche Sad. Influence of thermophysical wall properties during pool boiling on large diamond and SiC heaters. Heat Transfer Engineering. 2014;35:472-81.

[71] Rashidabad VN, Manteghian M, Masoumi M, Mousavian S, Ashouri D. Application of neural networks to predict changing the diameters of bubbles in pool boiling distilled water. International Journal of Chemical, Materials Science and Engineering. 2014;8:16-8.

[72] Chu IC, No HC, Song CH, Euh DJ. Observation of critical heat flux mechanism in horizontal pool boiling of saturated water. Nuclear Engineering and Design. 2014;279:189-99.

[73] Kumar V, Goel R. Heat transfer from horizontal surface to the pool of distilled water at atmospheric and sub atmospheric pressure. International Journal of Engineering and Management Technology. 2014;2:55-66.

[74] Utaka Y, Kashiwabara Y, Ozaki M, Chen Z. Heat transfer characteristics based on microlayer structure in nucleate pool boiling for water and ethanol. International Journal of Heat and Mass Transfer. 2014;68:479-88.

[75] Hariharan M, Kathiravan R, Kumar SS, Arunprasath M. Heat transfer analysis of pool boiling in stainless steel flat plate heater with water. International Journal of Scientific and Engineering Research. 2014;5:695-701.

[76] Xu X, Qian T. Single-bubble dynamics in pool boiling of one-component fluids. Physical Review E. 2014;89:063002.

[77] Hetsroni G, Moldavsky L, Fichman M, Pogrebnyak E, Mosyak A. Ultrasonic enhancement of subcooled pool boiling of freely oscillated wires. International Journal of Multiphase Flow. 2014;67:13-21.

[78] Chouarfa F, Benhamza MH, Bendjaballah M. New model of heat transfer in the process of nucleate boiling in a pool: prediction and assessment. Journal of Engineering Physics and Thermophysics. 2014;87:743-52. 
[79] Hamzekhani S, Falahieh MM, Akbari A. Bubble departure diameter in nucleate pool boiling at saturation: Pure liquids and binary mixtures. International Journal of Refrigeration. 2014;46:50-8.

[80] Das S, Kumar SD, Bhowmik S. Enhancement of nucleate pool boiling heat transfer on silicon oxide thin film surface. Procedia Engineering. 2014;90:530-7.

[81] Zakaria I, Michael Z, Mohamed WANW, Mamat AMI, Azmi WH, Mamat R, et al. A review of nanofluid adoption in polymer electrolyte membrane (PEM) fuel cells as an alternative coolant. Journal of Mechanical Engineering and Sciences. 2015;8:1351-66.

[82] Hussein AM, Sharma KV, Bakar RA, Kadirgama K. Heat transfer enhancement with nanofluids - A Review. Journal of Mechanical Engineering and Sciences. 2013;4:452-61.

[83] Azmi WH, Sharma KV, Mamat R, Anuar S. Nanofluid properties for forced convection heat transfer: An overview. Journal of Mechanical Engineering and Sciences. 2013;4:397-408.

[84] Bang IC, Chang SH. Boiling heat transfer performance and phenomena of Al $2 \mathrm{O}$ 3-water nano-fluids from a plain surface in a pool. International Journal of Heat and Mass Transfer. 2005;48:2407-19.

[85] Wen D, Ding Y. Experimental investigation into the pool boiling heat transfer of aqueous based $\gamma$-alumina nanofluids. Journal of Nanoparticle Research. 2005;7:265-74.

[86] Kim S, Bang IC, Buongiomo J, Hu L. Study of pool boiling and critical heat flux enhancement in nanofluids. Bulletin of the Polish Academy of Sciences-Technical Sciences. 2007;55:211-6.

[87] Chopkar M, Das A, Manna I, Das P. Pool boiling heat transfer characteristics of $\mathrm{ZrO} 2$-water nanofluids from a flat surface in a pool. Heat and Mass Transfer. 2008;44:999-1004.

[88] Witharana S, Uanreroro A, Chen H, Ding Y. Pool boiling of titania-water-ethylene glycol nanofluids. In: UK-China Particle Technology Forum. 2009;2:1-3.

[89] Phan HT, Caney N, Marty P, Colasson S, Gavillet J. Surface coating with nanofluids: the effects on pool boiling heat transfer. Nanoscale and Microscale Thermophysical Engineering. 2010;14:229-44.

[90] Xiao B, Jiang G, Chen L. A fractal study for nucleate pool boiling heat transfer of nanofluids. Science China Physics, Mechanics and Astronomy. 2010;53:30-7.

[91] Hegde R, Rao S, Reddy R. Investigations on boiling-induced nanoparticle coating, transient characteristics and effect of pressure in pool boiling heat transfer on a cylindrical surface. Experimental Heat Transfer. 2012;25:323-40.

[92] Syam Sundar L, Sharma KV. Laminar Convective heat transfer and friction factor of al2o3 nanofluid in circular tube fitted with twisted tape inserts. International Journal of Automotive and Mechanical Engineering. 2011;3:265-78.

[93] Hussein AM, Bakar RA, Kadirgama K, Sharma KV. Experimental measurements of nanofluids thermal properties. International Journal of Automotive and Mechanical Engineering. 2013;7:850-63.

[94] Abdolbaqi MK, Azwadi CSN, Mamat R, Azmi WH, Najafi GN. Nanofluids heat transfer enhancement through straight channel under turbulent flow. International Journal of Automotive and Mechanical Engineering. 2015;11:2294-305.

[95] Hsu CC, Su TW, Chen PH. Pool boiling of nanoparticle-modified surface with interlaced wettability. Nanoscale Research Letters. 2012;7:1-7. 
[96] Pal S, Bhaumik S. Development of theoretical correlation for prediction of boiling heat transfer using $\mathrm{TiO}_{2}$-water nanofluid. Energy and Biotechnology. 2012;33:348.

[97] Syam Sundar L, Sharma KV. An experimental study on heat transfer and friction factor of $\mathrm{Al}_{2} \mathrm{O}_{3}$ nanofluid. Journal of Mechanical Engineering and Sciences. 2011;1:99-112.

[98] Rao GS, Sharma KV, Chary SP, Bakar RA, Rahman MM, Kadirgama K, et al. Experimental study on heat transfer coefficient and friction factor of al2o3 nanofluid in a packed bed column. Journal of Mechanical Engineering and Sciences. 2011;1:1-15.

[99] Mahendran M, Lee GC, Sharma KV, Shahrani A. Performance of evacuated tube solar collector using water-based titanium oxide nanofluid. Journal of Mechanical Engineering and Sciences. 2012;3:301-10.

[100] Suriyawong A, Dalkilic A, Wongwises S. Nucleate pool boiling heat transfer correlation for $\mathrm{TiO}_{2}$-water nanofluids. Journal of ASTM International. 2012;9:112.

[101] Yang CT, Yu CC. Pool boiling of micro-/nanoparticles modified aluminum surface. Advances in Materials Science and Engineering. 2013;2013:1-6.

[102] Hiswankar SC, Kshirsagar JM. Determination of critical heat flux in pool boiling using $\mathrm{ZnO}$ nanofluids. International Journal of Engineering Research and Technology: ESRSA Publications; 2013. p. 2091-5.

[103] Zhang BJ, Kim KJ. Nucleate pool boiling heat transfer augmentation on hydrophobic self-assembly mono-layered alumina nano-porous surfaces. International Journal of Heat and Mass Transfer. 2014;73:551-61.

[104] Das S, Bhaumik S. A correlation for the prediction of heat flux for nucleate pool boiling heat transfer of nanofluid. Arabian Journal for Science and Engineering. 2014;39:4997-5006.

[105] Demir E, Izci T, Alagoz AS, Karabacak T, Koşar A. Effect of silicon nanorod length on horizontal nanostructured plates in pool boiling heat transfer with water. International Journal of Thermal Sciences. 2014;82:111-21.

[106] Xu Z, Zhao C. Influences of nanoparticles on pool boiling heat transfer in porous metals. Applied Thermal Engineering. 2014;65:34-41.

[107] Naphon P, Thongjing C. Pool boiling heat transfer characteristics of refrigerantnanoparticle mixtures. International Communications in Heat and Mass Transfer. 2014;52:84-9.

[108] Junjie G, HJ B. Estimation of pool boiling heat transfer coefficients of ethanolwater mixtures. Journal of Chemical Industry and Engineering. 1998;7:95-103.

[109] Kandlikar S, Alves L. Effects of surface tension and binary diffusion on pool boiling of dilute solutions: an experimental assessment. Journal of Heat Transfer. 1999;121:488-93.

[110] Hetsroni G, Zakin J, Lin Z, Mosyak A, Pancallo E, Rozenblit R. The effect of surfactants on bubble growth, wall thermal patterns and heat transfer in pool boiling. International Journal of Heat and Mass Transfer. 2001;44:485-97.

[111] Rao GV, Balakrishnan A. Heat transfer in nucleate pool boiling of multicomponent mixtures. Experimental Thermal and Fluid Science. 2004;29:87103.

[112] Ozdemir M, Pehlivan H. Prediction of the boiling temperature and heat flux in sugar-water solutions under pool-boiling conditions. Heat and Mass Transfer. 2008;44:827-33. 
[113] Fazel SA, Safekordi A, Jamialahmadi M. Pool boiling heat transfer in wateramines solutions. IJE Transactions A: Basics. 2008;21:113-30.

[114] Alam M, Agarwal V. Pool boiling of liquids \& their mixtures on enhanced surfaces at sub-atmospheric pressures. International Conference on Chemical \& Process Engineering Rome, Italy: Citeseer; 2009.

[115] Acharya A, Pise A, Momin I. Ammonium chloride as surfactant for heat transfer enhancement in pool boiling. International Journal of Engineering and Technology. 2011; 3(3): 323-6.

[116] Sathyabhama A, Krishnan V. Pool boiling heat transfer to water/lithium bromide mixture. International Conference on Challenges and Opportunities in Mechanical Engineering2012. p. 548-52.

[117] Sarafraz M, Peyghambarzadeh S. Nucleate pool boiling heat transfer to Al2O3water and $\mathrm{TiO} 2$-water nanofluids on horizontal smooth tubes with dissimilar homogeneous materials. Chemical and Biochemical Engineering Quarterly. 2012;26:199-206.

[118] Cardoso EM, Passos JC. Nucleate boiling of n-pentane in a horizontal confined space. Heat Transfer Engineering. 2013;34:470-8.

[119] Fazel SA, Sarafraz M, Shamsabadi AA, Peyghambarzadeh S. Pool boiling heat transfer in diluted water/glycerol binary solutions. Heat Transfer Engineering. 2013;34:828-37.

[120] Forrest EC, Hu L-W, Buongiorno J, McKrell TJ. Pool boiling heat transfer performance of a dielectric fluid with low global warming potential. Heat Transfer Engineering. 2013;34:1262-77.

[121] Fischer S, Herbert S, Slomski E, Stephan P. Local heat flux investigation during pool boiling single bubble cycles under reduced gravity. Heat Transfer Engineering. 2014;35:482-91.

[122] Gajghate S, Acharya A, Pise A. Experimental study of aqueous ammonium chloride in pool boiling heat transfer. Experimental Heat Transfer. 2014;27:11323.

[123] Hakeem M, Kamil M, Asif M. Prediction of pool boiling heat transfer coefficients in pool boiling of liquids using artificial neural network. Journal of Scientific and Industrial Research. 2014;73:536-40.

[124] Tiwari G, Prakash O, Kumar S. Evaluation of convective heat and mass transfer for pool boiling of sugarcane juice. Energy Conversion and Management. 2004;45:171-9.

[125] Kumar M, Kasana K, Kumar S, Prakash O. Evaluation of convective heat transfer coefficient for pool boiling of milk under closed condition. S-JPSET. 2010;1:919.

[126] Kumar M, Kasana K, Kumar S, Prakash O. Pool boiling of milk in a stainless steel pot under closed condition. International Journal of Current Research. 2011;3:949.

[127] Kumar M, Prakash O, Kasana K. An experimental study on the pool boiling heat transfer coefficient of milk. Facta Universitatis, Series Mechanical Engineering 2011;9:61-70.

[128] Kumar M, Prakash O, Kasana K. An experimental study on pool boiling of milk. Heat Transfer-Asian Research. 2011;40:159-70.

[129] Kumar M, Kasana K, Kumar S, Prakash O. Experimental evaluation of constants for the Rohsenow pool boiling correlation for khoa. SJPSET. 2011;2:21-6. 
[130] Filipczak G, Troniewski L, Witczak S. Pool boiling of liquid-liquid multiphase systems, evaporation, condensation and heat transfer. Evaporation, Condensation and Heat transfer. Eedited by Amimul Ahsan, Intech Publisher; 2011.

[131] Wei J, Yu B, Wang H. Heat transfer mechanisms in vapor mushroom region of saturated nucleate pool boiling. International Journal of Heat and Fluid Flow. 2003;24:210-22.

[132] Beitel G. Boiling heat-transfer processes and their application in the cooling of high heat flux devices. Arnold Engineering Development Center; 1993.

[133] Yasuo O, Tomoaki K. Numerical study on subcooled pool boiling. Progress in Nuclear Science and Technology. 2011;2:125-9.

[134] Golobic I, Pavlovic E, Von Hardenberg J, Berry M, Nelson R, Kenning D, et al. Comparison of a mechanistic model for nucleate boiling with experimental spatiotemporal data. Chemical Engineering Research and Design. 2004;82:1-10.

[135] Rudemiller GR. A fundamental study of boiling heat transfer mechanisms related to impulse drying. The Institute of Paper Science and Technology Atlanta Georgia1989.

[136] Mostinski I. Application of the rule of corresponding states for calculation of heat transfer and critical heat flux. Teploenergetika. 1963;4:66.

[137] Labuntsov D. Heat transfer problems with nucleate boiling of liquids. Thermal Engginering. 1973;19:21-8.

[138] Kutateladze SS. Heat transfer and hydrodynamic resistance: Handbook: Energoatomizdat Publishing House; 1990.

[139] Boyko-Kruzhilin. International Journal of Heat and Mass Transfer. 1967:10-361.

[140] Cooper M. Heat flow rates in saturated nucleate pool boiling: A wide ranging examination using reduced properties. Advances in Heat Transfer. 1984;16:157239.

[141] D. G. Pool boiling. VDI Heat Atlas. 1993.

[142] Cornwell K, Houston S. Nucleate pool boiling on horizontal tubes: a convectionbased correlation. International Journal of Heat and Mass Transfer. 1994;37:3039.

[143] Zuber N. Hydrodynamic aspects of boiling heat transfer California. USA: RamoWooldridge Corporations, Los Angeles; 1959. 